\title{
Importance of Studying Older Siblings of Patients Identified by Newborn Screening: a Single-Center Experience in Mexico
}

Journal of Inborn Errors of Metabolism \& Screening 2021, Volume 9: e20210001 DOI: https://doi.org/10.1590/2326-4594JIEMS-2021-0001

\author{
Isabel Ibarra-González ${ }^{1}$, Cynthia Fernández-Lainez ${ }^{2}$, Sara \\ Guillén-López ${ }^{2}$, Lizbeth López-Mejía², Leticia Belmont-Martínez², \\ Rosa Itzel Nieto-Carrillo ${ }^{2}$ and Marcela Vela-Amieva ${ }^{2}$
}

\begin{abstract}
Introduction: Any abnormal newborn screening (NBS) test should be subjected to appropriate diagnostic tests and should be followed. Once the newborn has been diagnosed and treated, the family should receive comprehensive genetic services.

Aim: To present the experience of studying older siblings of patients with inborn errors of metabolism (IEM) identified by NBS in a single-national follow-up reference center.

Methods: A retrospective analysis of medical files of the IEM patients detected by NBS was conducted. All those older siblings who tested positive for the same IEM of the patient detected by newborn screening were included.

Results: A total of 26 positive siblings from 18 families with seven different IEM were found (phenylketonuria, argininemia, glucose-6-phosphate dehydrogenase deficiency, 3-methylcrotonyl-CoA carboxylase deficiency, dihydropteridine reductase deficiency, tyrosinemia type 3 , and medium chain acyl-CoA dehydrogenase deficiency). The age range of the affected siblings was 2 to 19 years old, with a mean age of 8.5 years. Ten older siblings (38.5\%) had clinical consequences for the disease, including severe intellectual disability.
\end{abstract}

Conclusions: It is necessary to study older siblings, and family history and genetic counseling of all NBS-detected families should be recommended, especially in countries where expanded NBS programs are beginning.

Keywords: Neonatal screening, genetic counseling, inborn errors of metabolism, intellectual disability, hyperphenylalaninemia, clinical genetic services, follow up.

\section{Introduction}

Newborn screening (NBS) has proven to be an effective public health program to prevent or diminish the morbidity and mortality associated with a range of disorders [1-3]. Almost all the diseases detected by NBS are genetic, and most of them have an autosomal recessive mode of inheritance, which means that both parents are asymptomatic carriers and that in each pregnancy, there is a $25 \%$ risk of having an affected child [4].

Any abnormal NBS test should be subjected to appropriate diagnostic tests and must be closely followed, preferably in specialized reference centers $[5,6]$. Once the newborn has been diagnosed and appropriately treated, the family requires clinical genetic services that include accurate diagnosis, genetic counseling, linkage of patients with genetic service providers, communication with subspecialists, reproductive options, and the study of relatives considered to be at risk $[7,8,9]$. Thus, clinical genetic services are considered part of NBS follow-up activities [10].

In some high-income countries, follow-up NBS activities are carried out by metabolic teams in which geneticists and genetic counselors are fundamental members, along with other specialists, social workers, and metabolic nurses [1]. Even in those countries, there is variability in the access to genetic services [7];

\footnotetext{
${ }^{1}$ Instituto Nacional de Pediatría, Instituto de Investigaciones Biomédicas, Unidad de Genética de la Nutrición, UNAM, México.

${ }^{2}$ Instituto Nacional de Pediatría, Laboratorio de Errores Innatos del Metabolismo y Tamiz, Secretaría de Salud, México.
}

Received January 12, 2021, and in revised form March 08, 2021. Accepted for publication March 29, 2021.

\section{Corresponding Author:}

Marcela Vela-Amieva, Email: dravelaamieva@yahoo.com 
however, in middle- or low-income countries, NBS follow-up is performed by diverse professionals, including pediatricians or general practitioners, and the affected families do not always have access to genetic services. There are few published data on the provision of genetic services offered to families whose children were detected by NBS $[10,11]$, especially regarding the study of other affected family members.

In Mexico, where there are barriers to equal access to genetic services [12], the routine study of relatives at risk, especially previous siblings of the patients detected by NBS, is not always done, and not all families receive genetic counseling. The objective of this work was to present the experience of studying the older siblings of patients with inborn errors of metabolism (IEM) identified by NBS in a single-national follow-up reference center.

\section{Methods}

In this 2006-2020 retrospective study, the laboratory database, which included 133 patients detected by NBS, was reviewed, and families with more than one child were selected (Figure 1). All older sisters or brothers who tested positive for the same IEM of the patient detected by NBS were included. Confirmatory tests of organic acidemias and aminoacidopathies were performed as described below.

Urinary organic acid analysis using gas chromatography/ mass spectrometry: Extraction of organic acids from urine was performed according to the methodology previously reported by Sweetman et al. [13]. Briefly, urine aliquots equivalent to 60 $\mu \mathrm{g} / \mathrm{mL}$ creatinine were used for the extraction of organic acids. Organic acids were extracted from urine samples by liquidliquid extraction using ethyl acetate and hyperosmolar sodium chloride as contrasting liquid phases. Subsequently, the oxime form of the organic acids was obtained by a chemical reaction with hydroxylamine under alkaline conditions. Finally, the volatile forms of the oximated organic acids were obtained via a chemical reaction with trimethylsilyl silane (TMS). The oximated-TMS derivatives of the organic acids were analyzed by gas chromatography coupled with mass spectrometry.

Quantification of plasma amino acids by high-performance liquid chromatography was based on the methodology previously described by Qureshi et al. [14]. Free amino acids were extracted and separated from plasma samples by precipitation of proteins with pure ethanol and centrifugation. After filtering the samples with $0.22 \mu \mathrm{m}$ syringe filters, fluorescent derivatives of the amino acids were obtained by chemical reaction with a methanolic solution of $146 \mu \mathrm{M}$ o-phthalaldehyde in the presence of $2 \%$ ethanethiol. These amino acid derivatives were separated and quantified by reverse-phase high-resolution liquid chromatography coupled to fluorescent detection. Amino acid concentrations were calculated using $\mathrm{p}$-fluorophenylalanine as an internal standard.

Determination of blood amino acid and acylcarnitine profiles by tandem mass spectrometry was performed using a commercial kit from Perkin Elmer, according to the manufacturer's instructions. Briefly, dried blood spots obtained from the patient's heel prick were used for the extraction of AA and AC. For the extraction step, $190 \mu \mathrm{L}$ of a methanolic solution that already included the stable isotopes of AA and AC standards was used. After extraction, samples were introduced to tandem mass spectrometry equipment (triple quadrupole) with electrospray ionization for the quantification of AA and AC.

Differential diagnosis of hyperphenylalaninemias (HPAs) was performed by Sanger sequencing of phenylalanine and tetrahydrobiopterin metabolism genes from DNA extracted from dried blood spots. Patients with G6PDd were confirmed by Sanger sequencing of G6PD. Tyrosinemia-3 patients were confirmed by Sanger sequencing of the genes involved in tyrosine metabolism.

As part of our initial clinical survey, NBS performed on previous symptomatic siblings was intentionally questioned. The presence or absence of diagnostic odyssey, defined as the time passed (in years) from initial symptoms to final diagnosis or multiple medical referrals (more than three consultations with medical specialists) experienced by the patients was also recorded. Descriptive statistics were used for the analysis. Numerical variables are presented as means and percentages.

\section{Results}

A total of 26 positive siblings from 18 families with seven different diagnoses were identified. The age range of the affected siblings

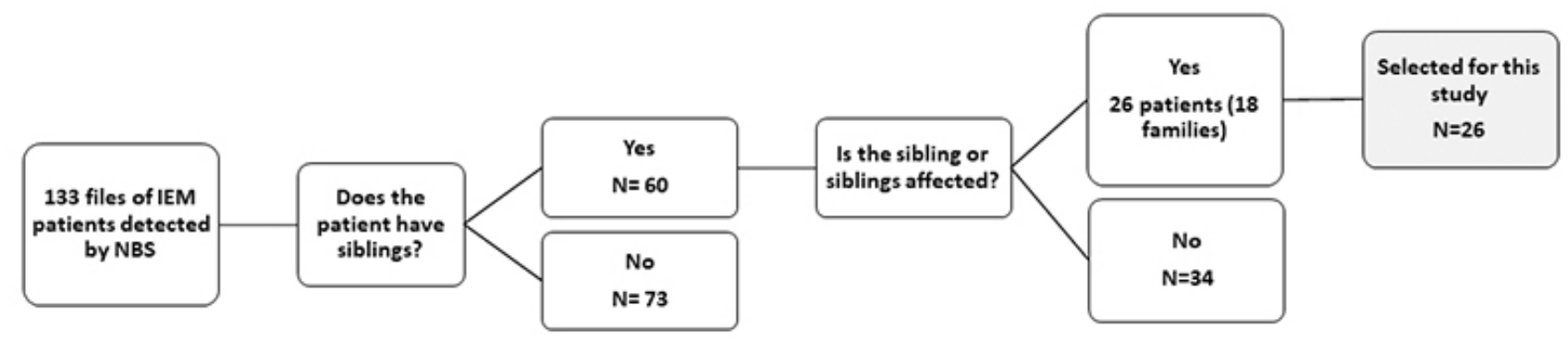

Figure 1. Study algorithm for inclusion of individuals in the present study. 
was 2 to 19 years old, with a mean age of 8.5 years. Non-deceased siblings were also recorded. Hyperphenylalaninemia (HPA) and glucose-6-phosphate dehydrogenase deficiency (G6PDd, MIM phenotype \# 300908) were the most frequent, with nine and four families, respectively. Two siblings had argininemia (ARG, MIM phenotype \# 207800), seven had 3-methylcrotonyl-CoA carboxylase deficiency (3MCC, MIM phenotype \# 210200), one sibling had medium chain acyl-CoA dehydrogenase deficiency (MCAD, MIM phenotype \# 201450), and one had tyrosinemia type 3 (4-hydroxyphenylpyruvic acid dioxygenase deficiency, MIM phenotype \# 276710) (Table 1).

\section{Health status of positive siblings at diagnosis}

1. Families with HPA. Phenylalanine hydroxylase (PAH, MIM\# 261600) and dihydropteridine reductase (DHPR, MIM phenotype \# 261630) deficiencies were found in patients with HPA, in a proportion of 8/9 and 1/9 families, respectively. Among the families with PAH deficiency, a total of 10 siblings were affected: five had benign HPA and were asymptomatic, and four had classic PKU; their clinical characteristics are shown in Table 2.

2. Families with G6PDd. All affected siblings with G6PDd were male $(4,15$, and 19 years old). Only one of them (3 years old) was symptomatic, and he had an antecedent of severe anemia that required blood transfusion, without a specific diagnosis.

3. Families with ARG. Three siblings from two families were identified. The first was an 11-year-old male patient with a clinical history of periodic hyperammonemia crisis, with seizures, spasticity, behavioral disorder, and intellectual disability, with several hospitalizations and no specific diagnosis. The other family has two siblings, one 3-year-old girl and an 8-year-old boy, both with severe gait alterations, chronic vomiting, history of enriched protein food rejection, malnutrition, neurological impairment, and several hospitalizations in the emergency room, without specific diagnosis.

4. Families with 3-MCC. Seven affected siblings were found, four males and three females with ages ranging from 3 to 19

Table 1. Number of older affected siblings and their ages.

\begin{tabular}{lcccc}
\hline Diagnosis & Number of families & $\begin{array}{c}\text { Number of affected } \\
\text { siblings }\end{array}$ & $\begin{array}{c}\text { Age range of affected } \\
\text { siblings (years) }\end{array}$ & Mean age (years) \\
\hline HPA* & 9 & 10 & $3-13$ & 6.2 \\
G6PDd & 4 & 4 & $3-19$ & 10.2 \\
ARG & 2 & 3 & $3-11$ & 7.3 \\
3 MCC & 1 & 7 & $3-17$ & 10.5 \\
MCAD & 1 & 1 & 10 & 10 \\
TYR-3 & 1 & 1 & 2 & 2 \\
TOTAL & $\mathbf{1 8}$ & $\mathbf{2 6}$ & $\mathbf{2 - 1 9}$ & $\mathbf{8 . 5}$ \\
\hline
\end{tabular}

*HPA includes PKU, benign HPA, and a DHPR case

Table 2. Clinical findings at initial consultation of older siblings diagnosed after the newborns with HPA detected by NBS. (The presence or absence of symptoms is represented with + or -, respectively; $n=10$ ).

\begin{tabular}{|c|c|c|c|c|c|c|c|c|c|c|}
\hline \multirow{2}{*}{$\begin{array}{l}\text { Clinical data } \\
\text { Sex }\end{array}$} & \multicolumn{5}{|c|}{ Benign HPA } & \multicolumn{4}{|c|}{ Classic PKU } & \multirow{2}{*}{$\frac{\text { DHPR }}{F}$} \\
\hline & $\mathrm{F}$ & M & M & $\mathrm{F}$ & $\mathrm{F}$ & $\mathrm{F}$ & $\mathrm{F}$ & $M$ & M & \\
\hline Age (years) & 3 & 9 & 9 & 8 & 6 & 5 & 13 & 8 & 6 & 5 \\
\hline Chronic eczema & - & - & - & - & - & + & ++ & ++ & + & + \\
\hline Hypopigmentation & - & - & - & - & - & + & ++ & + & + & ++ \\
\hline Chronic irritability & - & - & - & - & - & + & + & + & - & ++ \\
\hline Insomnia & - & - & - & - & - & + & + & + & - & + \\
\hline Hypotonia/dystonia & - & - & - & - & - & + & + & - & - & +++ \\
\hline Seizures & - & - & - & - & - & + & + & - & - & ++ \\
\hline Attention deficit & - & - & - & - & - & + & + & + & + & + \\
\hline Learning problems & - & - & - & - & - & + & + & + & + & +++ \\
\hline Hypoacusia & - & - & - & - & - & + & - & - & - & - \\
\hline Autistic traits & - & - & - & - & - & + & - & - & - & - \\
\hline Intellectual disability & - & - & - & - & - & + & ++ & + & + & +++ \\
\hline Asymptomatic & + & + & + & + & + & - & - & - & - & - \\
\hline
\end{tabular}


years old. All the subjects were asymptomatic, and none had a history of hospitalization or relevant health problems.

5. Family with MCAD. Only one totally asymptomatic 10 -years old sister was found.

6. Family with TYR-3. We found one 2-year-old brother with language delay, attention deficit, and mild neurodevelopmental delay (Table 1).
Once diagnosed, all symptomatic siblings with PKU, DHPR, ARG, G6PDd, and TYR-3 attended our specialized center for the initiation of appropriate treatment.

From the medical record survey, it was detected that NBS was performed on $9 / 10$ symptomatic siblings; however, it was not an expanded test, the panel applied was variable, and it did not include the metabolic disorder that affected the specific family. Therefore, the causes of NBS failure in these older siblings were recorded and are shown in Figure 2.

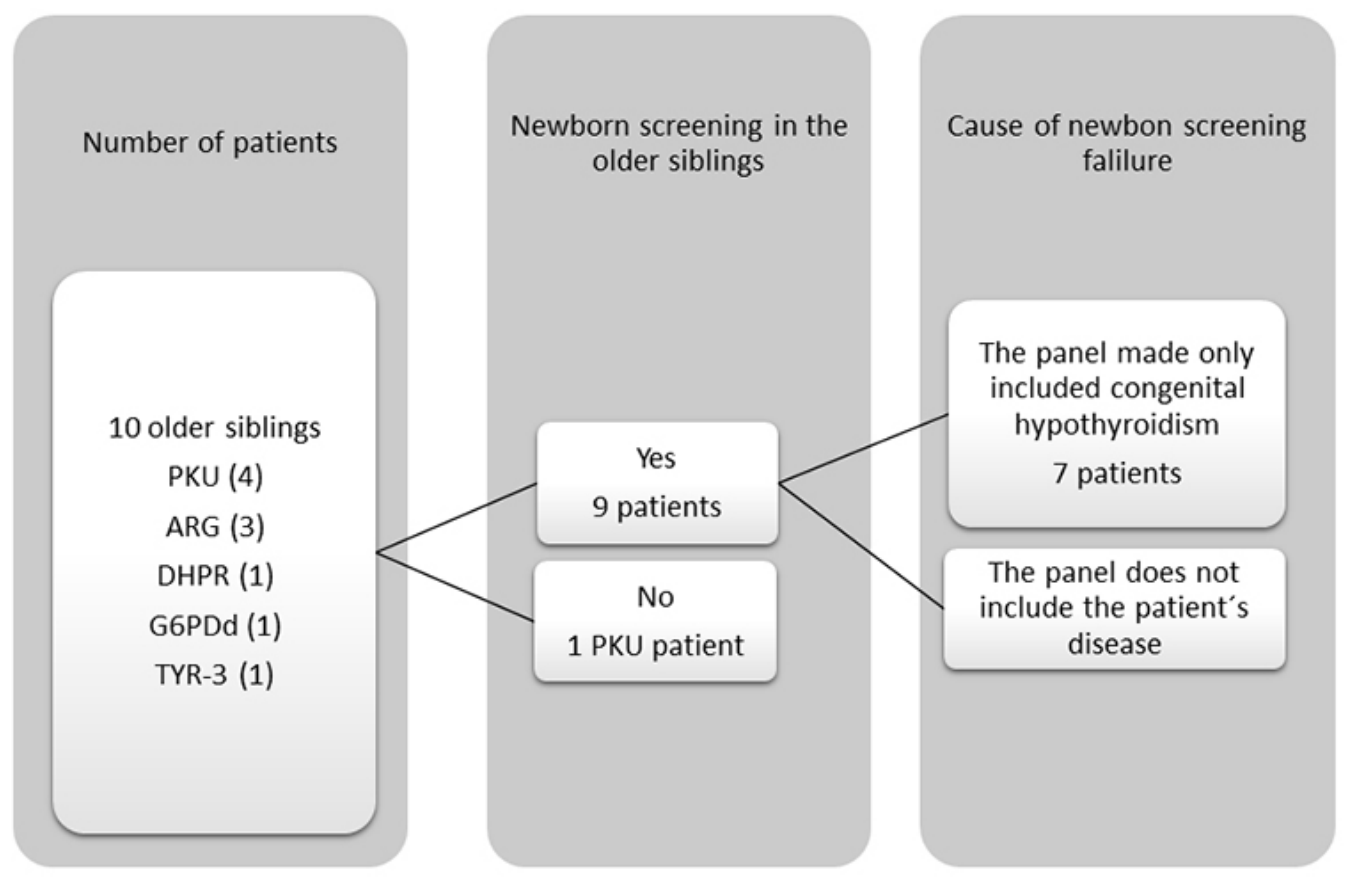

Figure 2. Causes of lack of early detection in the older symptomatic siblings $(n=10)$.

\section{Diagnostic odyssey and misdiagnosis of older siblings}

Furthermore, in cases where the siblings coursed with symptomatic forms of the disease, several medical services evaluated them. In most cases, physicians did not suspect the disease; in addition, some pediatricians were not able to detect early neurodevelopmental abnormalities, and in one case, misdiagnosis occurred (Table 3).

\section{Discussion}

The primary goal of NBS is to detect and treat infants with diverse diseases in a timely manner in order to prevent health impairment and infant mortality $[3,15]$; however, since most of the diseases detected by NBS are genetic, it is not uncommon to find other affected or deceased members in the family, especially older siblings, who carry the same condition [16]. Our results support this, since we found 26 affected older siblings, and $10(38.5 \%)$ of them had severe clinical consequences of the disease, including intellectual disability (Table 1). These findings are especially important for countries such as Mexico, where not all screened newborns with a positive result have access to genetic services that include genetic counseling. Genetic counseling is the process of helping people understand and adapt to the medical, psychological, and familial implications of genetic contributions of the disease, and to integrate the interpretation of medical history, education, and counseling to promote informed choices and adaptation to the risk or the condition [12,17]. Because of the poor accessibility to genetic services, not all patients detected by NBS have a complete family history, including the risk assessment of close relatives [18-20]. The study of older siblings of newborns detected by NBS has been strongly recommended by various authors [16,21,22], and our results agree with this suggestion.

In high-income countries such as the United States, it is known that among NBS programs, $66-74 \%$ routinely provide genetic counseling [21]; however, even in those countries with developed NBS programs, there are differences in the genetic 
Table 3. Characteristics of the diagnostic odyssey and misdiagnosis of the symptomatic siblings with IEM.

\begin{tabular}{|c|c|c|c|}
\hline $\begin{array}{c}\text { IEM } \\
(n=10 \text { patients })\end{array}$ & $\begin{array}{c}\text { Diagnostic odyssey presence } \\
\text { in patients }\end{array}$ & $\begin{array}{c}\text { Mean span of diagnostic } \\
\text { odyssey (years) }\end{array}$ & Misdiagnosis before IEM confirmation \\
\hline $\begin{array}{l}\text { Classic PKU } \\
(n=4)\end{array}$ & $3 / 4$ & 8.6 & $\begin{array}{l}\text { - Cerebral palsy } \\
\text { - Hypoxic-ischemic encephalopathy } \\
\text { - Unspecified motor and intellectual disability }\end{array}$ \\
\hline $\begin{array}{l}\text { DHPR } \\
(n=1)\end{array}$ & $1 / 1$ & 5 & $\begin{array}{l}\text { - Perinatal asphyxia } \\
\text { - Dystonia } \\
\text { - Unspecified motor and intellectual disability }\end{array}$ \\
\hline $\begin{array}{l}\text { ARG } \\
(n=3)\end{array}$ & $3 / 3$ & 7.3 & $\begin{array}{l}\text { - Spastic diplegia, } \\
\text { - Intellectual disability } \\
\text { - Epilepsy }\end{array}$ \\
\hline $\begin{array}{l}\text { TYR-3 } \\
(\mathrm{n}=1)\end{array}$ & No & - & - \\
\hline $\begin{array}{l}\text { G6PDd } \\
(n=1)\end{array}$ & No & - & - Unspecified hemolytic crisis \\
\hline Total & $7 / 10$ & 6.9 & \\
\hline
\end{tabular}

services [7], and genetic counseling can be provided by different trained professionals: genetic counselors, clinical geneticists, or pediatricians $[12,23,24]$. In Mexico, genetic counselors, as professionals, do not exist; therefore, genetic counseling and family history for detected NBS patients are provided by other professionals, and sometimes is not even given. Some alternatives to improve this situation could be to train professionals such as nurses or general practitioners to offer basic genetic counseling and genetic history [25] or promote the genetic counselor profession $[12,24]$. Family medical history is the compilation of all important medical and demographic information about the patient and their biological relatives. It should include, among other details, family composition (three generations), familial diseases (miscarriages, deaths of infants or children, malformations, biochemical disorders, sudden deaths, or neurologic or psychiatric disorders), and interactions and relationships [26].

For many years (1980-2015), the mandatory NBS program in Mexico only included the detection of congenital hypothyroidism $(\mathrm{CH})$. The coverage of public NBS programs for $\mathrm{CH}$ has made significant progress [27], and in 2015, the panel was extended to include PKU, congenital adrenal hyperplasia, galactosemia, and recently, G6PDd and cystic fibrosis [28]. However, the inclusion of other genetic disorders appears remote [29]. Currently, there is huge variability between NBS practices in Mexico; only a few public health institutions include an extended panel [30,31].

Regarding HPA disorders, we found a high number of benign forms (Table 2), and it is well known that PKU NBS programs can detect benign HPA forms, which otherwise have not been identified [32], since they are asymptomatic and do not require medical consultation. However, detecting them is important in order to provide adequate genetic counseling.

The main cause of failure in early detection in the studied families was the absence of an NBS test that included the specific disease, leading the affected siblings to follow the natural history of the disease [33] (Figure 2).

Even though most of the siblings coursed with the classical phenotype or severe form of diseases such as PKU or ARG, which made evident the clinical picture, physicians who evaluated patients were not able to detect and did not even suspect the presence of an inherited metabolic disorder and referred the patients to specialized centers (Table 3). This phenomenon has been previously described in other IEMs, such as maple syrup urine disease and PKU $[33,34]$. In this study group, we also found that $7 / 10$ older siblings had a diagnostic odyssey, and they were frequently misdiagnosed with unspecified motor and intellectual disability (Table 3). This situation is common in low-income countries and has been described for several IEMs [35-37]. Thus, training physicians in IEMs and in neurodevelopmental skills is imperative in order to favor early detection of patients and to prevent or ameliorate health damage.

The complexity of NBS follow-up has increased as this health program has expanded. As has been shown in the present study, evaluating older siblings makes us face asymptomatic forms of the diseases, such as those occurring in benign HPAs or 3MCC (Table 1). Usually, these benign forms of disease do not require therapeutic intervention and should only be monitored; however, detection causes anguish in the parents, who must receive adequate support and counseling. Interestingly, there is controversy regarding whether $3 \mathrm{MCC}$ should be deleted from NBS mandatory panels [38].

\section{Conclusions}

Our results show that $38.5 \%$ of older siblings of NBSdetected newborns were affected by the same disease and were symptomatic, including intellectual disability. It is imperative to study older siblings, whether they are symptomatic or not, 
and the family history and risk evaluation of siblings of all NBS-detected families should be performed, especially in low-or medium-income countries where expanded NBS programs are beginning. Once suspected patients are diagnosed, the whole family must be studied to search for affected undiagnosed siblings, intervene, and improve their quality of life.

\section{Funding}

This work was supported by the Research Funding of the National Institute of Pediatrics (Recursos Fiscales 2018-2020, Programa E022 Investigación y Desarrollo Tecnológico en Salud, Ciudad de México, México).

\section{Declaration of Conflicting Interests}

The author(s) declared no potential conflicts of interest with respect to the research, authorship, and/or publication of this article.

\section{References}

1. Centers for Disease Control and Prevention (CDC). Ten great public health achievements-United States, 20012010. MMWR Morb Mortal Wkly Rep. 2011;60(19):619623. https://www.cdc.gov/mmwr/preview/mmwrhtml/ mm6024a4.htm

2. March of Dimes. Newborn Screening Issue Brief. http:// www.marchofdimes.org/materials/issue-brief-newbornscreening-november-2014.pdf (Accessed November 2020).

3. Kemper AR, Boyle CA, Brosco JP, et al. Ensuring the Life-Span Benefits of Newborn Screening. Pediatrics. 2019;144(6):e20190904. doi:10.1542/peds.2019-0904

4. Saudubray JM, Garcia-Cazorla A. Inborn Errors of Metabolism Overview: Pathophysiology, Manifestations, Evaluation, and Management. Pediatr Clin North Am. 2018;65(2):179-208. doi:10.1016/j.pcl.2017.11.002

5. Sontag MK, Sarkar D, Comeau AM, et al. Case Definitions for Conditions Identified by Newborn Screening Public Health Surveillance. Int J Neonatal Screen. 2018;4(2):16. doi:10.3390/ijns4020016

6. Munck A, Delmas D, Audrézet MP, Lemonnier L, Cheillan D, Roussey M. Optimization of the French cystic fibrosis newborn screening programme by a centralized tracking process. J Med Screen. 2018;25(1):612. doi:10.1177/0969141317692611

7. Kaye CI, Livingston J, Canfield MA, Mann MY, LloydPuryear MA, Therrell Jr BL. Assuring clinical genetic services for newborns identified through U.S. newborn screening programs. Genet Med. 2007;9(8):518-527. doi:10.1097/gim.0b013e31812e6adb
8. Thompson DB, Ahrens MJ, LeRoy BS, Brown D, Berry SA. Newborn blood spot screening and genetic services: a survey of Minnesota primary care physicians. Genet Med. 2005;7(8):564-570. doi:10.1097/01.gim.0000177417.61006.a6

9. Comeau AM, Accurso FJ, White TB, et al. Guidelines for implementation of cystic fibrosis newborn screening programs: Cystic Fibrosis Foundation workshop report. Pediatrics. 2007;119(2):e495-e518. doi:10.1542/peds.20061993

10. Livingston J, Therrell BL Jr, Mann MY, et al. Tracking clinical genetic services for newborns identified through newborn dried bloodspot screening in the United Stateslessons learned. J Community Genet. 2011;2(4):191-200. doi:10.1007/s12687-011-0055-Z

11. Hartley JN, Greenberg CR, Mhanni AA. Genetic counseling in a busy pediatric metabolic practice. J Genet Couns. 2011;20(1):20-22. doi:10.1007/s10897-010-9324-y

12. Bucio D, Ormond KE, Hernandez D, Bustamante CD, Lopez Pineda A. A genetic counseling needs assessment of Mexico. Mol Genet Genomic Med. 2019;7(5):e668. doi: $10.1002 / \mathrm{mgg} 3.668$

13. Sweetman L. Organic Acid Analysis. In: Hommes A, ed. Techniques in Diagnostic Human Biochemical Genetics: A Laboratory Manual. New York: Wiley-Liss; 1991:143-176.

14. Qureshi GA, Fohlin L, Bergström J. Application of highperformance liquid chromatography to the determination of free amino acids in physiological fluids. J Chromatogr. 1984;297:91-100. doi:10.1016/s0021-9673(01)89032-4

15. Berry SA, Lloyd-Puryear MA, Watson MS. Longterm follow-up of newborn screening patients. Genet Med. 2010;12(Suppl):s267-s268. doi:10.1097/ gim.0b013e3181fea476

16. Munck A, Houssin E, Roussey M. The importance of sweat testing for older siblings of patients with cystic fibrosis identified by newborn screening. J Pediatr. 2009;155(6):928930.e1. doi:10.1016/j.jpeds.2009.06.018

17. Thangavelu M. Genetic Counseling in Developing Countries. Int J Hum Genet. 2016;16(3-4):86-88. doi:10.1 080/09723757.2016.11886282

18. The New York-Mid-Atlantic Consortium for Genetic and Newborn Screening Services. Understanding Genetics. Chapter 5, Genetic Counseling. Washington: Genetic Alliance; 2009. Available from: https://www.ncbi.nlm. nih.gov/books/nbk115552/

19. Peterson MM. The role of genetic counseling. In: Driscoll $\mathrm{CJ}$, McPherson B, eds. Newborn screening system: the complete perspective. Oxford: Plural Publishing; 2010: 167-185. 
20. Marcus G. The Role of the Genetic Counselor in Newborn Screening. N C Med J. 2019;80(1):39-40. doi:10.18043/ ncm.80.1.39

21. Farrell MH, Certain LK, Farrell PM. Genetic counseling and other risk communication services by newborn screening programs. Arch Pediatr Adolesc Med. 2001;155:120-126. doi:10.1001/archpedi.155.2.120

22. Bieth E, Nectoux J, Girardet A, Gruchy N, Mittre H, Laurans M, Guenet D, Brouard J, Gerard M. Genetic counseling for cystic fibrosis: A basic model with new challenges. Arch Pediatr. 2020;27(Suppl 1):es30-es34. doi:10.1016/ S0929-693X(20)30048-8

23. Acosta AX, Abé-Sandes K, Giugliani R, Bittles AH. Delivering genetic education and genetic counseling for rare diseases in rural Brazil. J Genet Couns. 2013;22(6):830834. doi:10.1007/s10897-013-9570-x

24. Laurino MY, Padilla CD. Genetic counseling training in the Philippines. J Genet Couns. 2013;22(6):865-868. doi:10.1007/s10897-013-9587-1

25. Treadwell MJ, Anie KA, Grant AM, Ofori-Acquah SF, Ohene-Frempong K. Using formative research to develop a counselor training program for newborn screening in Ghana. J Genet Couns. 2015;24(2):267-277. doi:10.1007/ s10897-014-9759-7

26. Bennett RL. Family Health History: The First Genetic Test in Precision Medicine. Med Clin North Am. 2019;103(6):957966. doi: 10.1016/j.mcna.2019.06.002

27. Vela-Amieva M, Gamboa-Cardiel S, Pérez-Andrade ME, Ortiz-Cortés J, González-Contreras CR, Ortega-Velázquez V. Epidemiology of congenital hypothyroidism in Mexico. Salud Publica Mex. 2004;46:141-148. doi:10.1590/s003636342004000200008

28. García Flores EP, Herrera Maldonado N, Hinojosa Trejo MA, Vergara Vázquez M, Halley Castillo ME. Avances y logros del programa de tamiz metabólico neonatal en México (2012-2018). Acta Pediatr Mex. 2018;39(Suppl 1): 57S-65S. doi:10.18233/apm39no6pp57s-65s1722

29. Therrell BL, Padilla CD, Loeber JG, Kneisser I, Saadallah A, Borrajo GJ, Adams J. Current status of newborn screening worldwide: 2015. Semin Perinatol. 2015;39(3):171-187. doi: 10.1053/j.semperi.2015.03.002
30. Vela-Amieva M, Belmont-Martínez L, Ibarra-González I, et al. Variabilidad interinstitucional del tamiz neonatal en México. Bol Med Hosp Infant Mex. 2009;66(5):431439. https://www.medigraphic.com/pdfs/bmhim/hi-2009/ hi095f.pdf

31. Trigo-Madrid M, Díaz-Gallardo J, Mar-Aldana R, et al. Resultados del Programa de Tamiz Neonatal Ampliado y epidemiología perinatal en los servicios de sanidad de la Secretaría de Marina Armada de México. Acta Pediatr Mex. 2014;35:448-458. https://www.medigraphic.com/ pdfs/actpedmex/apm-2014/apm146c.pdf

32. Blau N, van Spronsen FJ, Levy HL. Phenylketonuria. Lancet. 2010;376(9750):1417-1427. doi: 10.1016/S01406736(10)60961-0

33. Vela-Amieva M, Ibarra-González I, Fernández-Lainez $\mathrm{C}$, et al. Causes of delay in referral of patients with phenylketonuria to a specialized reference centre in Mexico. J Med Screen. 2011;18(3):115-120. doi: 10.1258/ jms.2011.011028

34. Ibarra-González I, Fernández-Lainez C, Belmont-Martínez L, et al. Elevada mortalidad y discapacidad en niños mexicanos con enfermedad de orina con olor a jarabe de arce (EOJA). Gac Med Mex. 2007;143(3):197-201. https:// www.medigraphic.com/pdfs/gaceta/gm-2007/gm073d.pdf

35. Ibarra-González I, Ridaura-Sanz C, Fernández-Lainez C, Guillén-López S, Belmont-Martínez L, Vela-Amieva M. Hepatorenal Tyrosinemia in Mexico: A Call to Action. Adv Exp Med Biol. 2017;959:147-156. doi: 10.1007/9783-319-55780-9_14

36. Márquez-Caraveo ME, Ibarra-González I, RodríguezValentín R, et al. Brief Report: Delayed Diagnosis of Treatable Inborn Errors of Metabolism in Children with Autism and Other Neurodevelopmental Disorders. J Autism Dev Disord. 2020. doi: 10.1007/s10803-020-04682-2

37. Black N, Martineau F, Manacorda T. Diagnostic odyssey for rare diseases: exploration of potential indicators. London: Policy Innovation Research Unit (PIRU); 2015. Available from: http://www.piru.ac.uk/assets/files/rare_diseases_ final_report.pdf

38. Wilcken B. 3-Methylcrotonyl-CoA carboxylase deficiency: to screen or not to screen? J Inherit Metab Dis. 2016;39(2):171-172. doi: 10.1007/s10545-015-9906-9 